\title{
Turbulence Model Effects on RANS Simulations of the HIFiRE Flight 2 Ground Test Configurations
}

\author{
Nicholas J. Georgiadis, Mina R. Mankbadi† and Manan A. Vyas ${ }^{\ddagger}$ \\ NASA Glenn Research Center, Cleveland, OH 44135
}

\begin{abstract}
The Wind-US Reynolds-averaged Navier-Stokes solver was applied to the Hypersonic International Flight Research Experimentation (HIFiRE) Flight 2 scramjet ground test configuration. Two test points corresponding to flight Mach numbers of 5.8 and 8.0 were examined. The emphasis was examining turbulence model effects on the prediction of flow path pressures. Three variants of the Menter $k-\omega$ turbulence model family were investigated. These include the baseline (BSL) and shear stress transport (SST) models as well as a modified SST model where the shear stress limiter was altered. Variations in the turbulent Schmidt number were also considered. Choice of turbulence model had a substantial effect on prediction of the flow path pressures. The BSL model produced the highest pressures and the SST model produced the lowest pressures. As expected, the settings for the turbulent Schmidt number also had significant effects on predicted pressures. Small values for the turbulent Schmidt number enabled more rapid mass transfer, faster combustion, and in turn higher flowpath pressures. Optimal settings for turbulence model and turbulent Schmidt number were found to be rather case dependent, as has been concluded in other scramjet investigations.
\end{abstract}

\section{Nomenclature}

speed of sound coefficient in SST model used to limit turbulent shear stress specific heat at constant pressure turbulent species diffusivity switching function in SST model $\left(F_{2}=1.0\right.$ for the inner three-fourths of a boundary layer; $F_{2}$ drops to 0.0 near the boundary layer edge) turbulent kinetic energy turbulent thermal conductivity turbulent Mach number static pressure total pressure turbulent Prandtl number turbulent Schmidt number static temperature total temperature Cartesian coordinates wall normal coordinate dynamic eddy viscosity specific turbulent dissipation rate $=\epsilon / k$ vorticity magnitude fuel equivalence ratio for primary (upstream) injectors

\footnotetext{
*Aerospace Engineer, Inlet and Nozzle Branch, AIAA Associate Fellow

${ }^{\dagger}$ Aerospace Engineer, Inlet and Nozzle Branch, AIAA Member

$¥$ Aerospace Engineer, Inlet and Nozzle Branch, AIAA Member
} 


$\begin{array}{ll}\phi_{s 1} & \text { fuel equivalence ratio for secondary (downstream) injectors } \\ \phi_{\text {total }} & \text { total fuel equivalence ratio } \\ \rho & \text { density }\end{array}$

\section{Introduction}

This report summarizes efforts to apply the Wind-US Reynolds-averaged Navier-Stokes (RANS) flow solver $^{1,2}$ to the Hypersonic International Flight Research (HIFiRE) Direct-Connect Rig (HDCR) scramjet ground test configurations. Computational fluid dynamics (CFD) simulations have been obtained for the same geometries and two of the flow conditions, corresponding to Mach 5.8 and Mach 8.0 flight, as those obtained with the VULCAN and CFD++ codes by Storch et al. ${ }^{3}$

The HIFiRE program has focused on improving the understanding of hypersonic flow physics. The objective of the HIFiRE Flight 2 ground tests and ultimately flight tests was on supersonic combustion performance. HIFiRE Flight 2 ground experimental data was obtained in the NASA Langley Arc-Heated Scramjet Test Facility (AHSTF). ${ }^{4}$ A combination of ethylene and methane fuels was used as a surrogate for more complex hydrocarbon fuels that are under consideration for future scramjet use. An overview of the experimental program is provided in Refs. 5 and 6 . The experimental work was coupled with computational analyses as discussed by Bynum and Baurle ${ }^{7}$ and Storch et al. ${ }^{3}$ wherein computational models were calibrated to both dual mode and scramjet mode operation. Flight experiments of the HIFiRE Flight 2 scramjet were successfully conducted in $2012 .{ }^{6}$

Other CFD investigations of the HIFiRE Flight 2 flow path include those described in Yentsch and Gaitonde $^{8}$ and Liu and Gruber. ${ }^{9}$ The latter served as preliminary work leading to that described in Ref. 3. In this study, emphasis is placed on turbulence modeling effects. It has been found for other scramjet analyses ${ }^{10}$ that the underlying turbulence model and modeling of scalar transport (i.e. settings for the turbulent Prandtl number and Schmidt number) have substantial effects on flow path predictions. Turbulencechemistry interactions are also of importance but were not investigated here.

The objective of this work was to determine the sensitivity of scramjet solutions to RANS modeling parameters for a range of flow conditions, and not to tune any particular turbulence model settings to one or multiple cases. It is important to understand the capabilities and limitations of RANS modeling for this class of flows that feature several very difficult challenges to currently available turbulence models. While some research into developing and applying advanced techniques such as hybrid RANS / Large Eddy Simulation (LES) will hopefully result in improved predictive capabilities in the not too distant future, RANS remains the practical state-of-the-art for scramjet analyses and probably will remain so in the near term.

\section{Flow Cases}

Wind-US simulations of the HIFiRE HDCR configurations were obtained for both tare and fueled conditions corresponding to Mach 5.8 and Mach 8.0 simulated flight. The flow conditions for these cases are shown in Table 1. For the fueled cases, the combustor fuel consisted of methane and ethylene, with the methane mole fraction $=0.36$. A schematic of the flow path, taken from Storch et al. ${ }^{3}$ and Cabell, ${ }^{11}$ is shown in Fig. 1. The flow path domain studied included the facility nozzle, isolator, cavity, combustor, and expansion nozzle. The primary injectors (P1) are located near the end of the isolator and secondary injectors (S1) are positioned just beyond the cavity. The cavity injectors (CI) depicted in the schematic were not used. The facility nozzle, not shown in this figure but included in the CFD model, is located just upstream of the isolator entrance. Note that the entire domain shown in Fig. 1 is 28 inches long. The flow path width is 4 inches throughout. The pressure distributions herein are always presented with $x=0$ positioned at the beginning of the isolator.

\section{Computational Settings}

\section{Grids}

The computational grids used in this study originated at NASA Langley and were employed in the studies of Ref. 3 for use with turbulence model wall functions, to alleviate the need for tight grid packing. The 
Table 1. Operating Conditions

\begin{tabular}{lccccc}
\hline Case & $T_{t}\left({ }^{\circ} R\right)$ & $P_{t}($ psi $)$ & $\phi_{p 1}$ & $\phi_{s 1}$ & $\phi_{\text {total }}$ \\
\hline \hline Tare, Mach 5.8 & 2790 & 215 & 0.00 & 0.00 & 0.00 \\
Tare, Mach 8.0 & 4625 & 620 & 0.00 & 0.00 & 0.00 \\
Reacting Flow, Mach 5.8 & 2790 & 215 & 0.15 & 0.50 & 0.65 \\
Reacting Flow, Mach 8.0 & 4625 & 620 & 0.40 & 0.60 & 1.00 \\
\hline
\end{tabular}

Mach 5.8 and 8.0 geometries were identical with the exception of the facility nozzle, where the Mach 8.0 configuration was designed to provide a higher isolator entrance Mach number. To take advantage of the two symmetry planes, grids were constructed for one quadrant of the overall configuration, thereby reducing computational cost. For the calculations discussed in this report, the grids were modified such that points were packed more tightly to the wall in order to use a wall-integration approach. The first points off the wall corresponded to a $y^{+}$of approximately 1-3, based on reference flow conditions. All of the walls were modeled as viscous no-slip boundaries with turbulent flow everywhere through the scramjet flow path except in the fuel injector zones where the flow was assumed to be laminar.

The unheated injector walls were treated as adiabatic. The direct connect facility nozzle walls were set to $900^{\circ} R$. All other scramjet flow path walls downstream of the nozzle were set to $1440^{\circ} R$. Reference 11 discusses heat transfer measurements made during the experiment and some limited wall temperature measurements. It is extremely difficult to make detailed measurements of wall temperatures throughout the flow path because of the extremely harsh environment. Due to the uncertainty of the actual wall temperatures, calculations where the wall temperature was varied by several hundred degrees from $1440^{\circ} R$ were examined. The resulting solutions showed indistinguishable differences between pressure predictions obtained with significantly different wall temperatures.

The overall grid sizes remained close to the original sizes at approximately 6.8 million points. While the wall packing was modified substantially, the axial grid distribution remained similar to the original grids. The grids were broken into 39 zones for parallel processing on the NASA Pleiades supercomputer.

\section{Turbulence Modeling}

Three variants of the Menter ${ }^{12} k-\omega$ model family were used to model the effects of turbulence in this study. The first was the Shear Stress Transport (SST) model that has become one of the most widely used turbulence models for RANS analyses. This model has been shown to be robust and relatively accurate for a broad range of flows, including wall boundary layers and free shear layer regions. For small separations due to mild adverse pressure gradients in subsonic flows, the model has generally performed as well as other readily available one- or two-equation turbulence models. However, in a recent shock-wave turbulent boundary-layer interaction (SWTBLI) workshop sponsored by the AIAA, ${ }^{13-15}$ it was found that the SST model tends to overpredict the size of flow separations in SWTBLI problems. In Ref. 12, Menter also introduced a similar k$\omega$ model, the baseline (BSL) model, which conversely tends to underpredict the magnitude of shock-induced separations. The BSL formulation was the second $k-\omega$ variant used here.

Due to the large differences between BSL and SST calculations of shock induced flow separations, on opposite extremes of experimental data, we recently investigated the distinguishing aspect of the SST model, the shear stress limiter. An extensive comparison of the BSL, SST, and variants of the SST model was reported in Ref. 16. The third turbulence model used in this work is one of these variants where the key coefficient in the SST model, $a_{1}$, was altered. This coefficient limits the modeled shear stress to not exceed the turbulent kinetic energy in the inner three-fourths of the boundary layer by a prescribed fraction. This is accomplished via the eddy viscosity expression, shown in Eqn. 1.

$$
\mu_{t}=\frac{\rho a_{1} k}{\max \left(a_{1} \omega, F_{2} \Omega\right)}=\min \left(\frac{\rho k}{\omega}, \frac{\rho a_{1} k}{F_{2} \Omega}\right)
$$

The default setting for $a_{1}$ was set to 0.31 in Menter ${ }^{12}$ based on primarily subsonic experience. However, in Ref. 16, examination of experimental data and computational solutions for SWTBLI problems indicated that 
a larger value for $a_{1}$ yields improved predictions of SWTBLI dominated flows. While a universal value for $a_{1}$ may not be achievable, $a_{1}=0.355$ yielded better results for SWTBLI problems than SST or BSL and was the value for $a_{1}$ used for the third turbulence modeling approach emphasized here. With the direct-connect flowpath considered in this case having significant flow regions with SWTBLIs from the isolator through the combustor, it was anticipated that the selection of turbulence model would have a large effect on flow path predictions.

In Ref. 3, VULCAN CFD code simulations were obtained using the BSL model and the CFD++ simulations were obtained with a nonlinear $k-\epsilon$ model. Both sets of simulations employed wall functions. In addition, for simulations obtained with both of these codes, a turbulent compressibility correction was not used for the dual-mode cases but was employed for the higher Mach number scramjet mode cases. Compressibility corrections were not used for any of the calculations considered here with Wind-US. Typical compressibility corrections operate by increasing the turbulent dissipation rate when the turbulent Mach number given by Eqn. 2 becomes of appreciable magnitude.

$$
M_{t}=\sqrt{2 k / a^{2}}
$$

It is not common practice to turn such a compressibility correction on for a subset of cases but then off for another subset. Nearly all other studies using a compressibility correction have had the correction on for all cases considered, and allow the functional form of the correction to have greater effect at higher values of $M_{t}$.

\section{Fuel and Combustion Modeling}

A reduced-order, finite rate chemistry model for combustion of methane and ethylene, having 8 species and 4 reactions, was employed for these studies. This model is a direct extension of the 6 species, 3 reaction step kinetics model for combustion of ethylene described in Baurle and Eklund ${ }^{17}$ and also used by Engblom et al. ${ }^{18}$

To achieve the desired fuel levels for primary (upstream) and secondary (downstream) fuel injectors, the total pressure needed to be iterated upon at the inflows to the injectors, while the fuel total temperature was held fixed at $540^{\circ} R$. Recalling that the computational domain modeled only a quadrant of the experimental configuration, there were two primary injectors and two secondary injectors in the computational model (eight primary and eight secondary injectors in the experiment). For the Mach 5.8 fueled case, setting the total pressures for both of the primary injectors to the same value resulted in significantly different fuel rates, but replicates the experimental situation where one supply line fed each set (i.e. primary or secondary sets) of fuel injectors. The different flow rates from the primary injectors were due to the local pressure field near each hole, which varied across the span. For both Mach numbers, the fuel inflow total pressures were adjusted after sets of iterations to try to match the measured fuel rate in the experiments. At Mach 5.8, these primary injector flow rates oscillated. This required an examination of each injector's mass flow over several oscillation periods, corresponding to several thousand iterations, to determine an average fuel mass flow rate. Table 2 shows the total pressures set at the primary injector inflows that were required in order to provide the desired $\phi_{p 1}=0.15$.

The primary fuel injector nearest the sidewall had the higher fuel rate, which was due to the thick boundary layer in that region and the resultant lower back pressures that this injector experienced relative to the primary injector closer to the centerline. The secondary injectors were choked and provided very similar flow rates. The secondary total pressure was set to 97.5 psi for the Mach 5.8 simulations. At the Mach 8.0 condition, the primary injectors provided very similar fuel flow rates but did not oscillate, making the simulation process more straightforward than for the Mach 5.8 condition. The secondary injectors were also choked at Mach 8.0. The primary injectors total pressure was set to 29.0 psi and the secondary injectors were set to $83.2 \mathrm{psi}$.

When using eddy viscosity models such as the $k-\omega$ employed here, the ultimate quantity that is taken to the Navier-Stokes equations to model the turbulent stresses is the eddy viscosity, $\mu_{t}$. In most RANS codes, a constant turbulent Prandtl number is used to extend the eddy viscosity to model the effects of turbulent thermal transport via the relation:

$$
\operatorname{Pr}_{t}=\mu_{t} C_{p} / k_{t}
$$


Table 2. Required primary injector total pressure for Mach 5.8 cases.

\begin{tabular}{ccc}
\hline Turbulence Model & $S c_{t}$ & $P_{t}($ psi $)$ \\
\hline \hline BSL & 0.4 & 39.0 \\
BSL & 0.5 & 37.7 \\
BSL & 0.6 & 36.3 \\
BSL & 0.7 & 35.1 \\
SST with $a_{1}=0.355$ & 0.4 & 36.8 \\
SST with $a_{1}=0.355$ & 0.5 & 35.6 \\
SST with $a_{1}=0.355$ & 0.6 & 34.3 \\
SST with $a_{1}=0.355$ & 0.7 & 33.1 \\
SST & 0.4 & 33.9 \\
SST & 0.5 & 32.9 \\
SST & 0.6 & 31.5 \\
SST & 0.7 & 29.4 \\
\hline
\end{tabular}

The turbulent mass diffusivity is modeled in a similar manner via the turbulent Schmidt number:

$$
S c_{t}=\mu_{t} / D_{t}
$$

In many aerodynamic applications at low Mach numbers and without chemical reactions or significant heat transfer effects, the air can be reasonably treated as a calorically perfect gas. Also, a constant turbulent Prandtl number on the order of unity is typically used and no species transport equations need to be solved. However, the turbulent Prandtl and Schmidt numbers have significant effects for the supersonic combustion problems that are the focus of this study.

The turbulent Prandtl number was set to 0.89 for all cases discussed here. However, the turbulent Schmidt number was varied for the reacting flow simulations. In previous studies, such as that of Ref. 3, the turbulent Schmidt number was set to 0.6 for the Mach 5.8 flight condition and 0.3 for the Mach 8.0 flight condition based on values determined to be the "best practice" settings used with CFD ++. In RANS simulations of scramjet flows, it has been found that the turbulent Schmidt number is one of the most important turbulence modeling parameters, typically having a more pronounced effect on the predictions than the turbulent Prandtl number. ${ }^{10,19}$ Lower turbulent Schmidt numbers simulate more effective turbulent mixing of species, resulting in more effective combustion relative to simulations obtained with larger values of the turbulent Schmidt number.

\section{Results}

\section{Tare Cases}

Figure 2(a) shows the effect that grid resolution has on tare solutions for the Mach 5.8 flight condition using the SST model. There are minimal differences between static pressure distributions obtained with the entire grid, termed the fine grid, and the medium grid which is generated by using every other point in each computational direction. While the focus of this section is on the tare cases, a comparison of solutions using these two grids for the fueled Mach 8.0 case is presented in Fig. 2(b). Figure 2 demonstrates that the pressure predictions are relatively insensitive to the grid resolution for both tare and fueled cases. As a result of this observation, the medium grid was used for all other simulations discussed in this paper because of the computational savings. Note that in all of the pressure distribution plots, there are two sets of experimental data: one denoted "body-side" and the other denoted "cowl-side." These refer to the walls of the ground test article with fuel injectors as would be oriented in the flight vehicle.

Predictions using the three turbulence models for the Mach 5.8 tare condition are presented in Fig. 3. All three solutions are identical up to the beginning of the combustor cavity (near $\mathrm{x}=11.5$ in). Note that pressures predicted by the SST model differ the most from the other two solutions in the cavity and 
combustor.

The Mach 8.0 tare computations are compared to experimental data in Fig. 4. Again, there are minimal differences among the solutions until the beginning of the combustor cavity. Note that through the isolator, the computed pressures are noticeably higher than the experimental values. This finding is consistent with the work of Storch et al. ${ }^{3}$ and that of Yentsch and Gaitonde. ${ }^{8}$ One theory discussed in Ref. 11 is that the quickly expanded flow in this case may result in frozen thermal non-equilibrium effects that produce the lower experimentally observed pressures. Thermal non-equilibrium effects were not modeled in this work nor in any of the previously cited studies. Another discrepancy between the simulations and experiment was that the post-test measurements of the throat area indicated a 6 percent decrease in throat area, which would result in a larger nozzle expansion ratio leading to lower pressures.

\section{Reacting Cases}

Mach number contours for the two reacting flow cases are illustrated in Fig. 5. The contours shown are from the simulation using SST with modified limiter, $a_{1}=0.355$. The core flow in the isolator for the Mach 5.8 flight condition is approximately Mach 2.5 upstream of the primary fuel injectors, while for the Mach 8.0 flight condition, the core flow Mach number is approximately 3.5.

Contours of static temperature and flowpath Mach number for the Mach 5.8 case are provided in Fig. 6 . In particular, the static temperature contours indicate where combustion is occurring within the flowpath. It may be observed that the primary injectors for the Mach 5.8 case are only providing a small fraction of the overall fuel. Fig. 7 shows an enlarged view of these two contours plots surrounding the primary injector nearest the sidewall, while Fig. 8 shows the same contour plots surrounding the primary injector nearest the centerline. In the Flow Conditions section previously mentioned, the flow tended to oscillate near the primary injectors at the Mach 5.8 flight condition. These figures also confirm the observation that the primary injector nearest the scramjet sidewall experienced a lower effective back pressure due to the thick corner boundary layer and, as a result, had a higher fuel flow rate than that of the injector nearest the centerline. Figure 9 shows an enlarged view of the temperature field surrounding the secondary injector nearest the sidewall. It may be observed that there is significantly greater combustion and heat release owing to the higher fuel flow rate from the secondary injectors, in comparison with the primary injectors.

Similar contour plots for the Mach 8.0 case are shown in Figs. 10 through 13. The temperature contours show more combustion activity in the cavity region than for Mach 5.8, which corresponds to the significantly higher fuel rate provided by the primary injectors. The zoomed contours in Figs. 11 and 12 also depict the higher fuel flow rates coming out of both primary injectors. Unlike the Mach 5.8 cases, the fuel rates from the primary injector nearest the sidewall and the injector nearest the centerline were nearly identical for the Mach 8.0 cases. The Mach 8.0 cases also did not oscillate because they did not have as large SWTBLIs near the primary injectors as did the Mach 5.8 cases.

Figures 14 through 16 demonstrate the variation in flow path pressures for the Mach 5.8 case that resulted from the unsteadiness of the flow near the primary injectors. In this region, the SWTBLIs created large flow separations that were unsteady in nature. While the CFD simulations were not run in a truly time accurate manner, examining the solutions over many thousand iterations revealed a periodic behavior. As a result of this observation, an ensemble averaging was used to produce average pressure distributions that are presented in subsequent figures. Two turbulent Schmidt numbers were examined for each of the three turbulence model variants. The $S c_{t}=0.4$ cases enabled greater mixing of species and more rapid combustion than the $S c_{t}=0.7$ cases. Figures 14 to 16 show that this leads to more steady flow in the $S c_{t}=0.4$ cases than the $S c_{t}=0.7$ cases.

Ensemble-averaged static pressure predictions made for the Mach 5.8 flight condition, using SST with $a_{1}=0.355$ and several values of $S c_{t}$, are provided in Fig. 17. As expected, there is noticeable variation in the solutions beginning in the region near the primary injectors and extending into the cavity and the combustor. In the cavity, the highest pressures correspond to the lowest $S c_{t}$ and in turn, the greatest turbulent species diffusion. These trends are simlar for the Mach 8.0 cases. However, Fig. 18 shows that the variation in solutions is not as pronounced. The range in $S c_{t}$ for these cases (0.2 to 0.6) reflects a factor of three change in the turbulent species diffusivity. It appears that $S c_{t}$ effects are more pronounced in ramjet or dual-mode operation rather than in scramjet operation.

Figures 19 and 20 provide comparisons of solutions when varying the turbulence model but holding $S c_{t}$ fixed. For these fueled cases, the greatest discrepancy between solutions obtained with the different turbulence model approaches is found in the region from the end of the isolator through the cavity. In all 
cases, the BSL model predicted the highest pressures and the SST model predicted the lowest pressures. The primary reason for this is the limiting of the turbulent shear stress in the SST model but not by the BSL model. At the end of the isolator with the first appearance of SWTBLIs, this difference in turbulence model limiter results in significantly different sized flow separation predictions. As discussed previously, the setting for the SST limiter has substantial effect on flows with SWTBLIs, which is definitely one of the key flow features of scramjet flow physics. The pressure in the region considered here rose as $a_{1}$ was increased from the lowest value (0.31) for the default SST model up to the unlimited value for the BSL model.

\section{Conclusions}

Wind-US was applied to the HIFiRE ground test configuration at unfueled (tare) and fueled conditions corresponding to Mach 5.8 and Mach 8 simulated flight. Computed flowpath pressures were compared to ground test measurements. The Wind-US simulations were obtained in a similar manner to those previously obtained using VULCAN and CFD++ reported in Storch et al. ${ }^{3}$ The primary objective of the current work was to examine the effect that turbulence modeling has on the prediction of flow path pressures. Three variants of the Menter $k-\omega$ turbulence model family were investigated. These models were the baseline (BSL) and shear stress transport (SST) models as well as the SST model with altered shear stress limiter. Variations in the turbulent Schmidt number were also considered. Choice of turbulence model had a strong influence on predicted scramjet flow path pressures. The BSL model produced the highest pressures and the SST model produced the lowest pressures. This was found to be due to differences in the SWTBLI induced flow separations predicted by the different turbulence models. The choice of turbulent Schmidt number also had a substantial effect on flow predictions.

Unfortunately, a single choice in turbulence model and turbulent Schmidt number would not provide optimal solutions for all of the cases considered in this study. This is a consistent observation of the scramjet analysis community. A calibration of the turbulence model and turbulent Schmidt number as a function of flow conditions may be of some utility in helping interpret experimental data. However, the problem still remains that the required calibration and the underlying modeling limitations prevents RANS CFD from being used as a predictive tool for new configurations, that is for a new scramjet geometry and/or operating conditions.

\section{Recommendations}

As has been discussed before in many reports such as the overview papers of Baurle ${ }^{19}$ and Georgiadis et al. ${ }^{10}$ there is a tremendous need for improvements in physical modeling for scramjet flow fields. As computing power continually improves, Large Eddy Simulations (LES) and hybrid RANS-LES models are becoming more feasible, and in some cases a better option than RANS, for some aerodynamic problems. However, predictions of shock-wave turbulent boundary-layer interactions (SWTBLIs) that dominate scramjet propulsion flowpaths are not likely to improve with LES or hybrid RANS-LES in the near future. The reason is that the near wall modeling is crucial, and currently available techniques have not yet demonstrated significant improvements over RANS methods. In the combustor, LES based techniques may offer some promise, but the range of scales important in the scramjet combustion process is broad, and it has been shown to date that there is significant sensitivity to subgrid modeling, grid density, and turbulence-chemistry interactions.

While there is hope that advanced techniques such as hybrid RANS-LES models may improve predictive capability, there is still a great need for improved turbulence modeling whether the model is used in pure RANS mode, or as the underlying RANS portion of the hybrid technique. Broader experience in using LES and the hybrid techniques in the reacting flow regions is needed to determine the current state-of-the-art, computing resources required, and areas of modeling advancements that are needed.

\section{Acknowledgements}

The authors would like to thank Mr. Michael Bynum and Ms. Andrea Storch of NASA Langley for supplying experimental data and their computational grids that were used to build the Wind-US models. They also provided other guidance that greatly assisted with the simulations discussed in this report. This work was sponsored by the NASA Fundamental Aeronautics Programs' Hypersonics and Aeronautical Sciences Projects. 


\section{References}

${ }^{1}$ Georgiadis, N. J., Yoder, D. A., Towne, C. E., Engblom, W. A., Bhagwandin, V., Power, G. D., Lankford, D. W., and Nelson, C. C., "Wind-US Physical Modeling Improvements to Complement Hypersonic Testing and Evaluation," AIAA Paper 2009-193, Jan. 2009.

${ }^{2}$ Nelson, C., "An Overview of the NPARC Alliance's Wind-US Flow Solver," AIAA Paper 2010-27, January 2010.

${ }^{3}$ Storch, A. M., Bynum, M., Liu, J., and Gruber, M., "Combustor Operability and Performance Verification for HIFiRE Flight 2," AIAA Paper 2011-2249, April 2011.

${ }^{4}$ Guy, R. W., Rogers, R. C., Puster, R. L., Rock, K. E., and Diskin, G. S., "The NASA Langley Scramjet Test Complex," AIAA Paper 96-3243, July 1996.

${ }^{5}$ Jackson, K. R., Gruber, M. R., and Barhorst, T. F., "The HIFiRE Flight 2 Experiment: An Overview and Status Update," AIAA Paper 2009-5029, Aug. 2009.

${ }^{6}$ Jackson, K., Gruber, M., and Buccellato, S., "HIFiRE Flight 2-A Program Overview," AIAA Paper 2013-0695, Jan. 2013.

${ }^{7}$ Bynum, M. D. and Baurle, R. A., "Design of Experiments Study for the HIFiRE Flight 2 Ground Test Computational Fluid Dynamic Results," AIAA Paper 2011-2203, April 2011.

${ }^{8}$ Yentsch, R. J. and Gaitonde, D. V., "Numerical Investigation of the HIFiRE-2 Scramjet Flowpath," AIAA Paper 20130119, Jan. 2013.

${ }^{9}$ Liu, J. and Gruber, M., "Preliminary Preflight CFD Study on the HIFiRE Flight 2 Experiment," AIAA Paper 2011-2204, April 2011.

${ }^{10}$ Georgiadis, N. J., Yoder, D. A., Vyas, M. A., and Engblom, W. A., "Status of Turbulence Modeling for Hypersonic Propulsion Flowpaths," AIAA Paper 2011-5917, July 2011.

${ }^{11}$ Cabell, K., Hass, N., Storch, A., and Gruber, M., "HIFiRE Direct-Connect Rig (HDCR) Phase I Scramjet Test Results from the NASA Langley Arc-Heated Scramjet Test Facility," AIAA Paper 2011-2248, April 2011.

${ }^{12}$ Menter, F. R., "Zonal Two Equation $k-\omega$ Turbulence Models for Aerodynamic Flows," AIAA Journal, Vol. 32, No. 8, 1994, pp. 1598-1605.

${ }^{13}$ DeBonis, J. R., Oberkampf, W. L., Wolf, R. T., Orkwis, P. D., Turner, M. G., Babinsky, H., and Benek, J. A., "Assessment of Computational Fluid Dynamics and Experimental Data for Shock Boundary-Layer Interactions," AIAA Journal, Vol. 50, No. 4, 2012, pp. 891-903.

${ }^{14}$ Benek, J., "Overview of the 2010 AIAA Shock Boundary Layer Interaction Workshop," AIAA Paper 2010-4821, January 2010.

${ }^{15}$ Benek, J. and Babinsky, H., "Lessons Learned from the 2010 AIAA Shock Boundary Layer Interaction Workshop," AIAA Paper 2010-4825, January 2010.

${ }^{16}$ Georgiadis, N. J. and Yoder, D. A., "Recalibration of the Shear Stress Transport Model to Improve Calculation of Shock Separated Flows," AIAA Paper 2013-0685, January 2013.

${ }^{17}$ Baurle, R. and Eklund, D., "Analysis of Dual-Mode Hydrocarbon Scramjet Operation at Mach 4-6.5," Journal of Propulsion and Power, Vol. 18, No. 5, Sept. 2002, pp. 990-1002.

${ }^{18}$ Engblom, W. A., Frate, F. C., and Nelson, C. C., "Progress in Validation of Wind-US for Ramjet/Scramjet Combustion," AIAA Paper 2005-1000, Jan. 2005.

${ }^{19}$ Baurle, R. A., "Modeling of High Speed Reacting Flows: Established Practices and Future Challenges," AIAA Paper 2004-267, Jan. 2004.

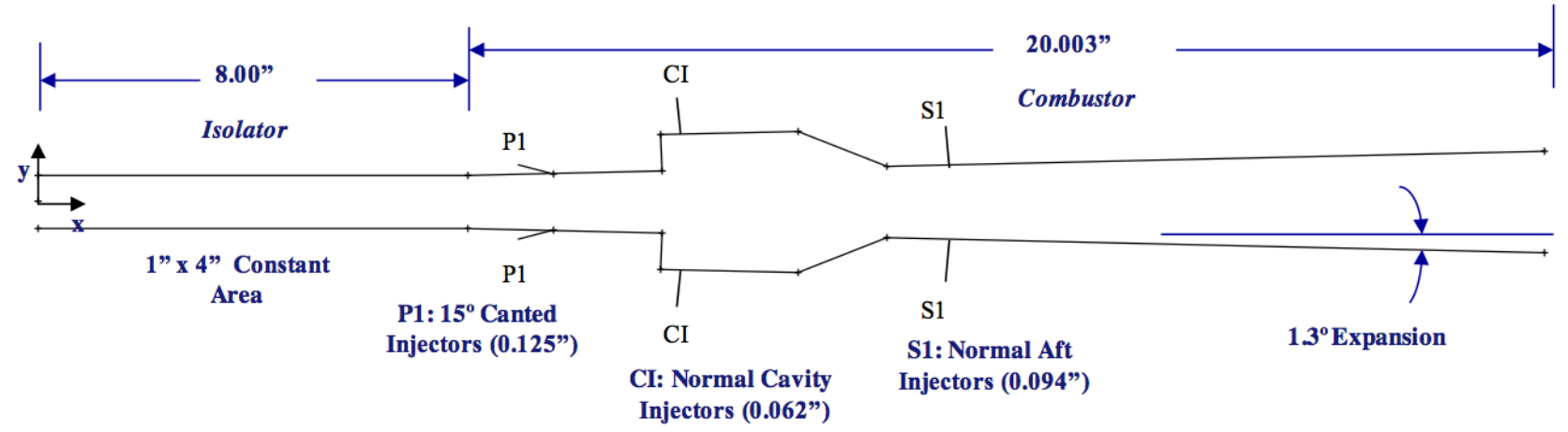

Figure 1. Schematic of scramjet flow path, taken from Storch et al. ${ }^{3}$ and Cabell. ${ }^{11}$ 


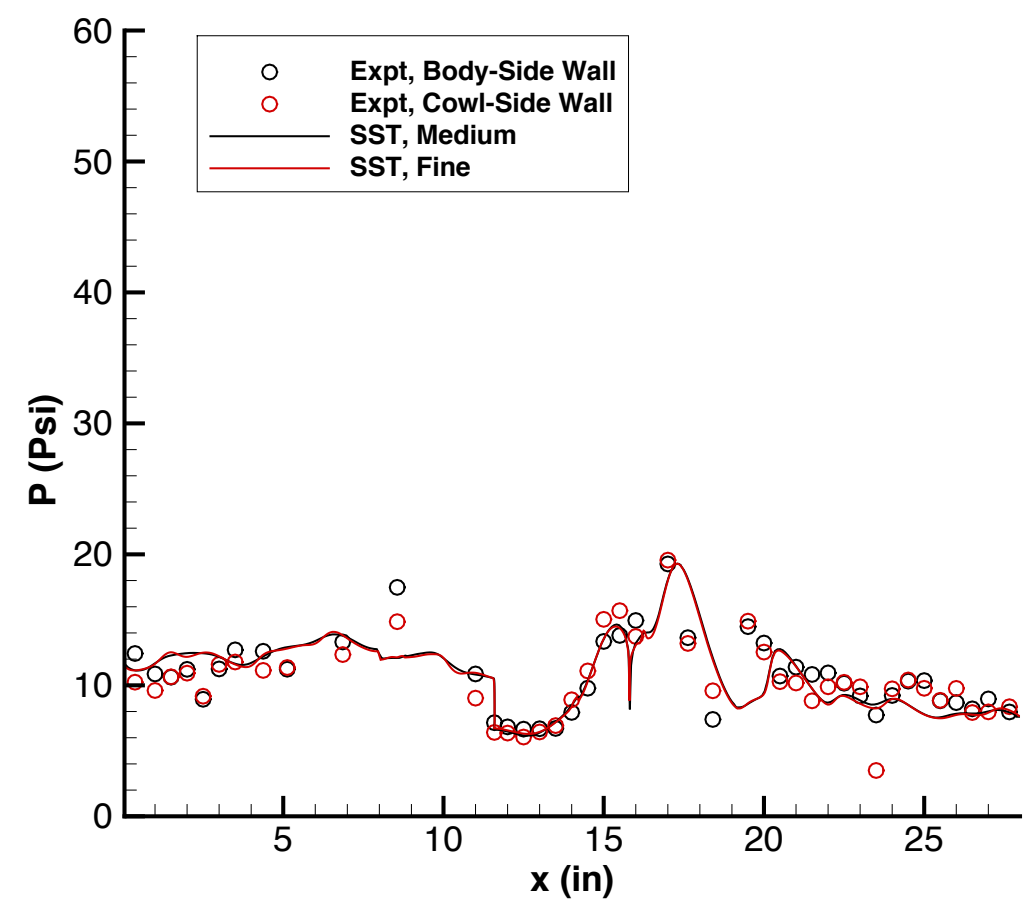

(a) Mach 5.8 flight condition, fuel off, using SST model

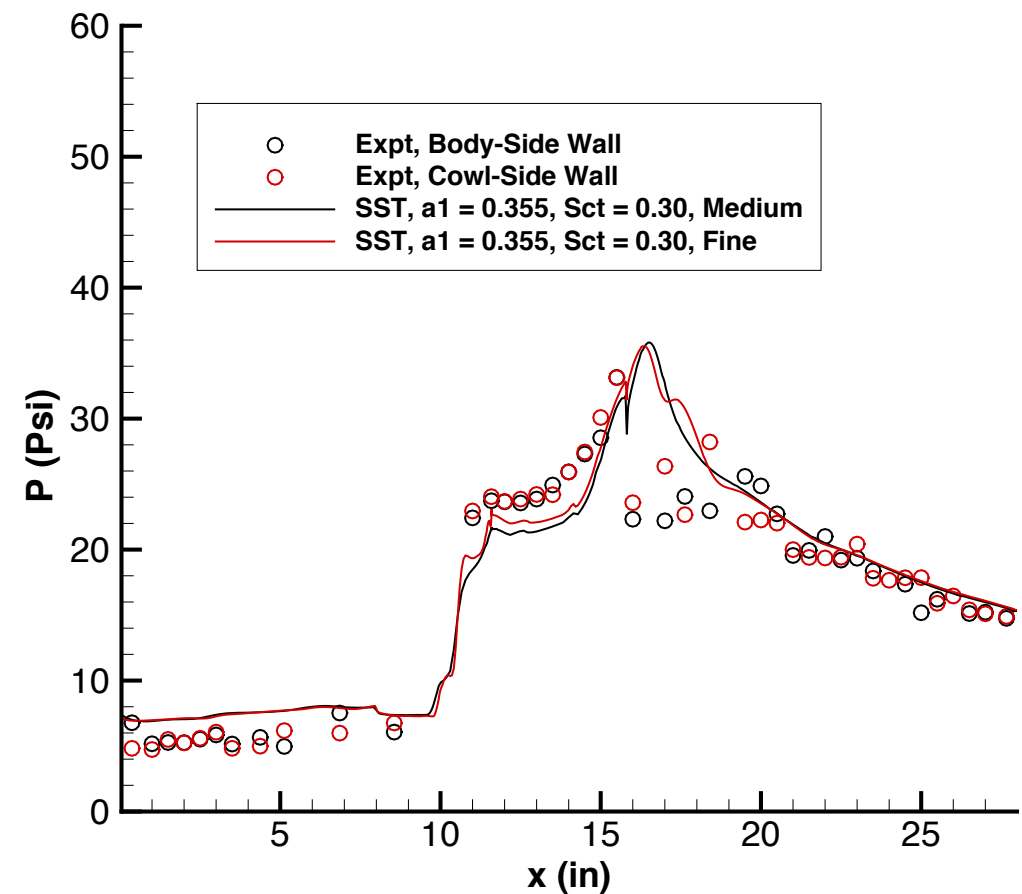

(b) Mach 8.0 flight condition, fueled, using SST model, $a_{1}=0.355, S c_{t}=0.3$

Figure 2. Grid sensitivity investigations. 


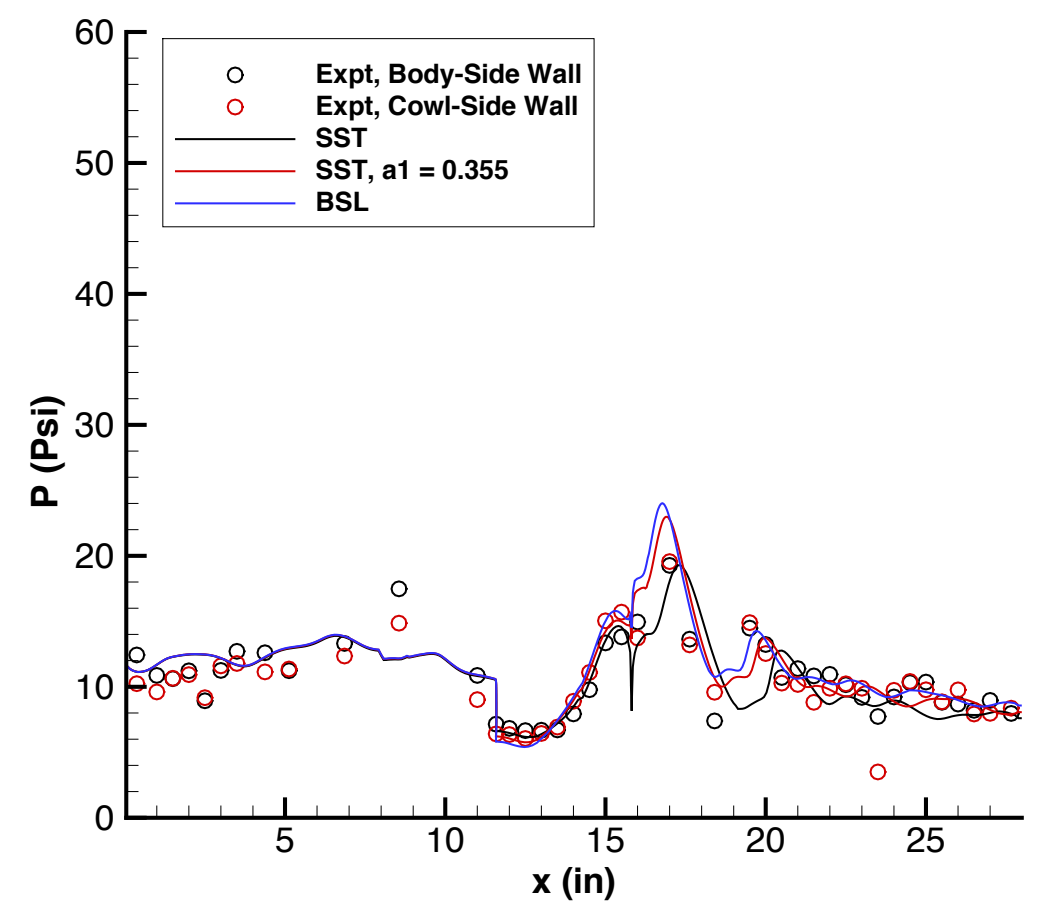

Figure 3. Static pressure distributions for the Mach 5.8 flight condition, fuel-off, turbulence model investigations.

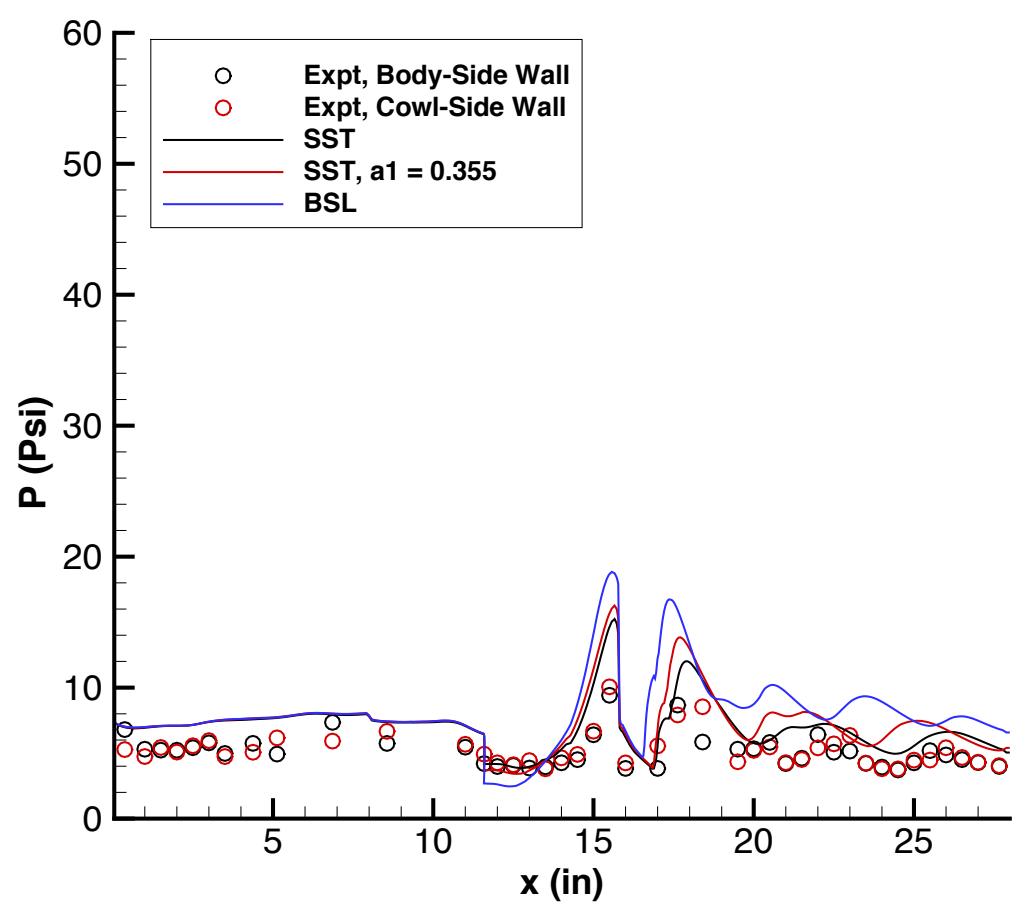

Figure 4. Static pressure distributions for the Mach 8 flight condition, fuel-off, turbulence model investigations. 

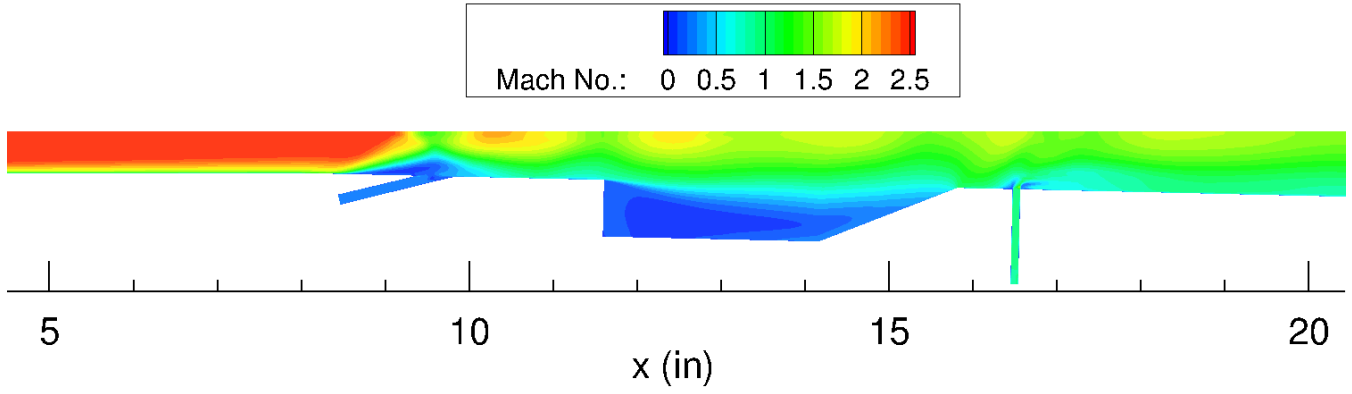

(a) Mach 5.8 flight condition

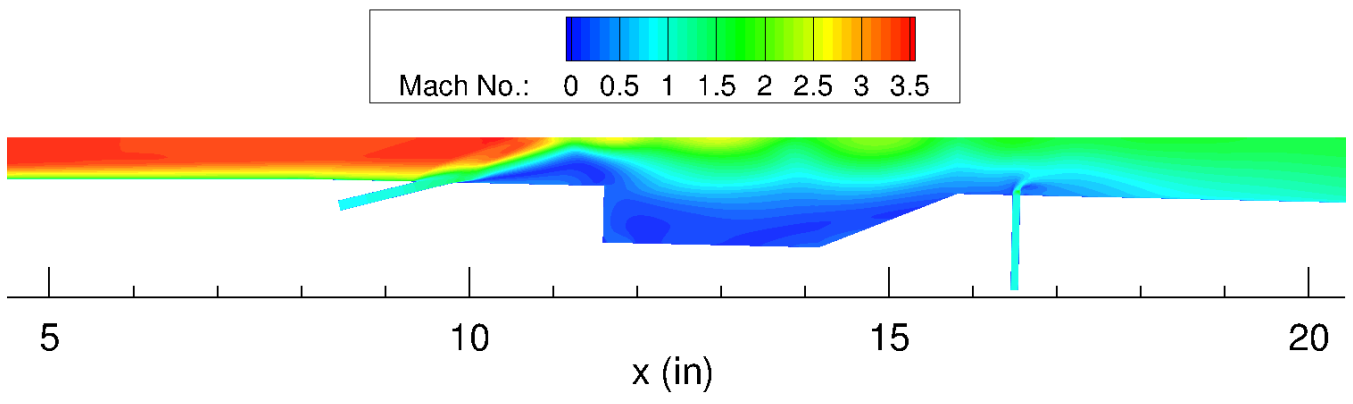

(b) Mach 8.0 flight condition

Figure 5. Mach number contours through injectors nearest centerline for HIFiRE simulations, fuel-on cases, using SST, $a_{1}=0.355$ turbulence model, $S c_{t}=0.6$ for Mach 5.8 and $S c_{t}=0.3$ for Mach 8.0. Same for subsequent contour plots (Figs. 6 through 13).

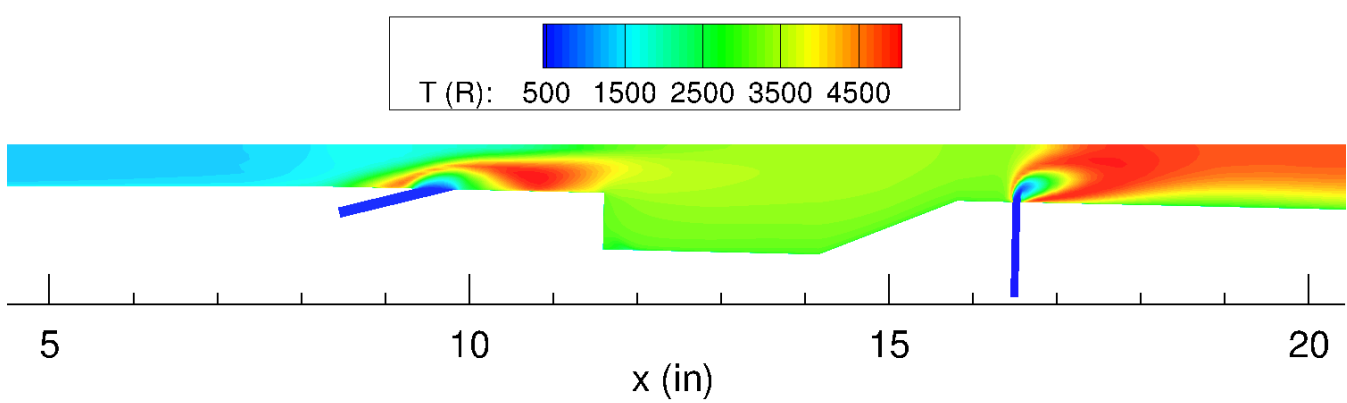

(a) Static temperature

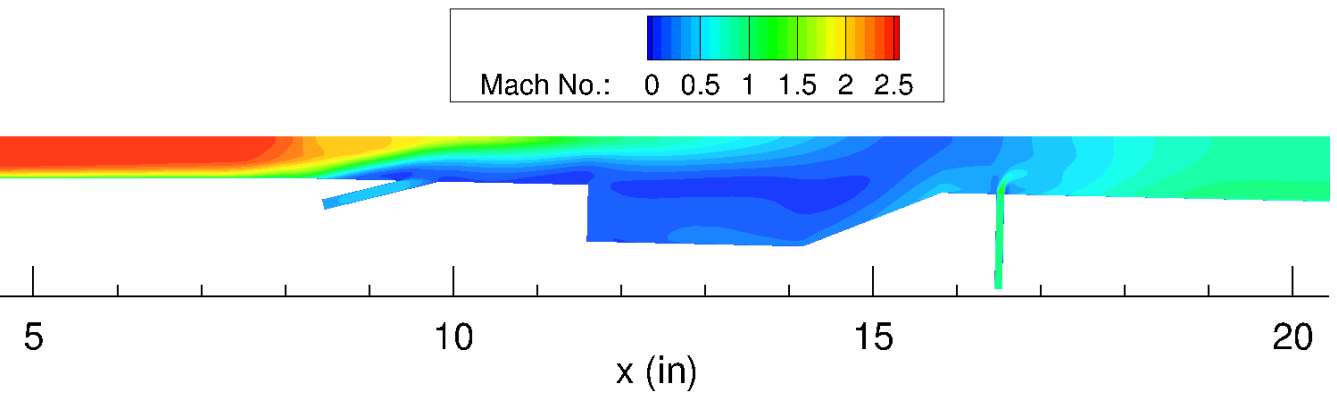

(b) Mach number

Figure 6. Calculated combustor flow field through injectors near sidewall for the Mach 5.8 case. 


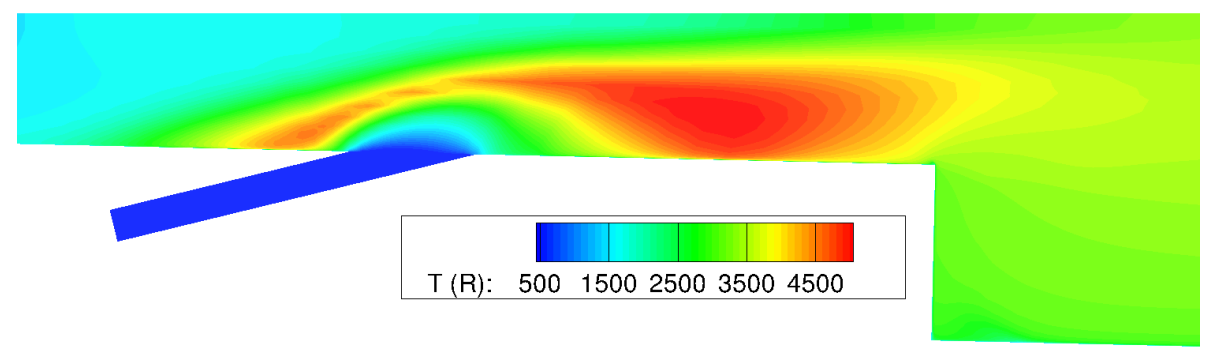

(a) Static temperature

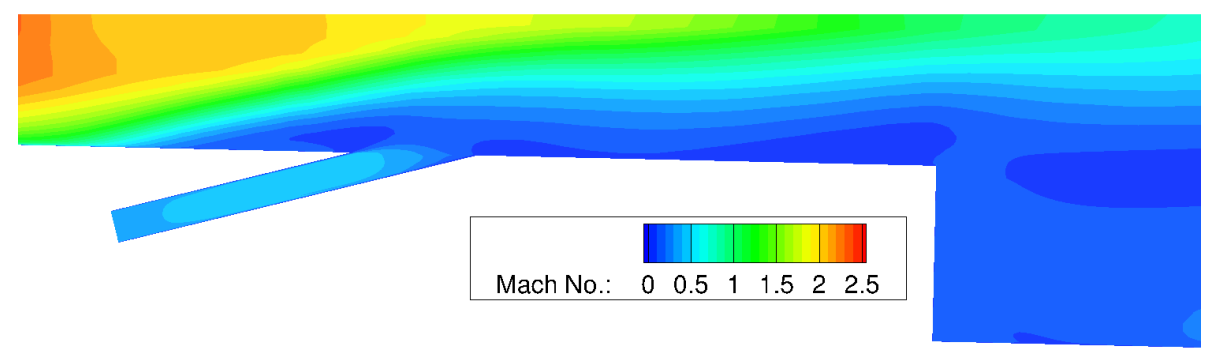

(b) Mach number

Figure 7. Closeup view of calculated combustor flow field surrounding primary injector near sidewall for the Mach 5.8 case.

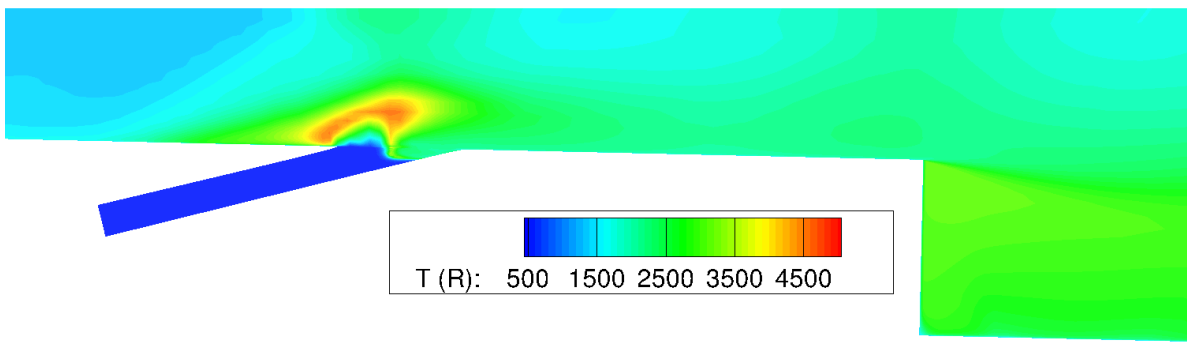

(a) Static temperature

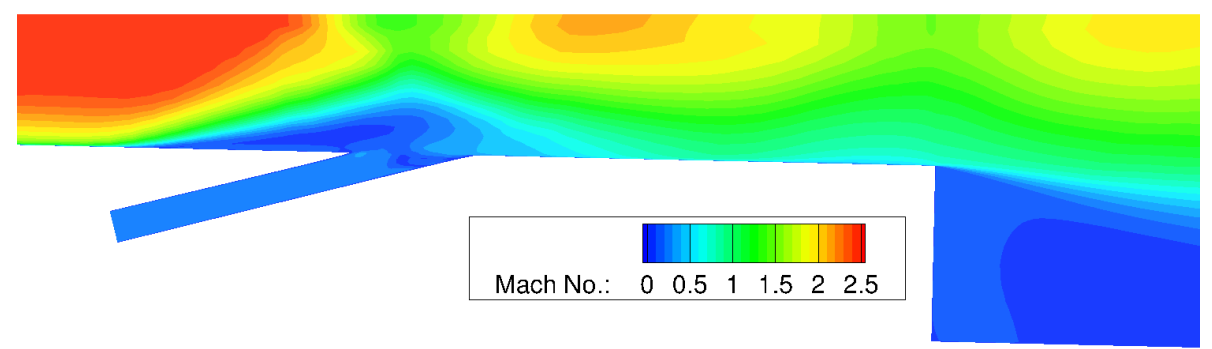

(b) Mach number

Figure 8. Closeup view of calculated combustor flow field through injectors nearest centerline for the Mach 5.8 case. 


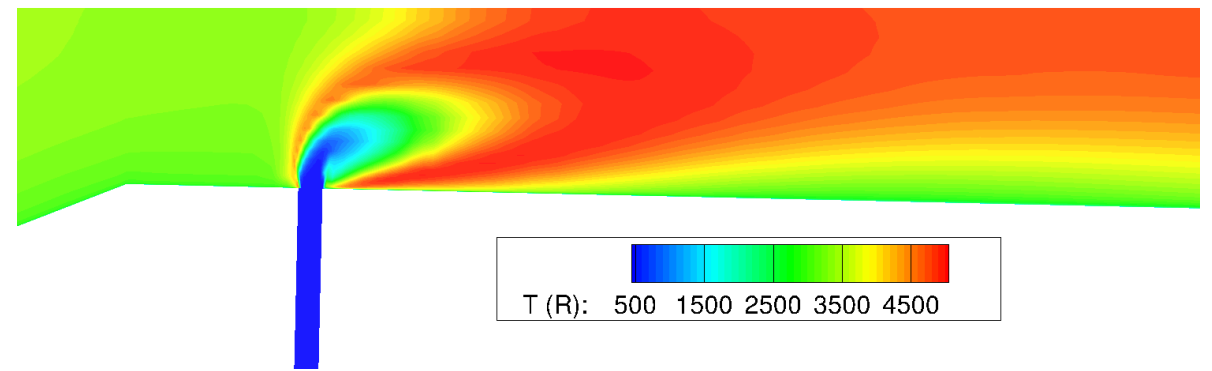

Figure 9. Closeup view of calculated combustor temperature field surrounding secondary injector near sidewall for the Mach 5.8 case.

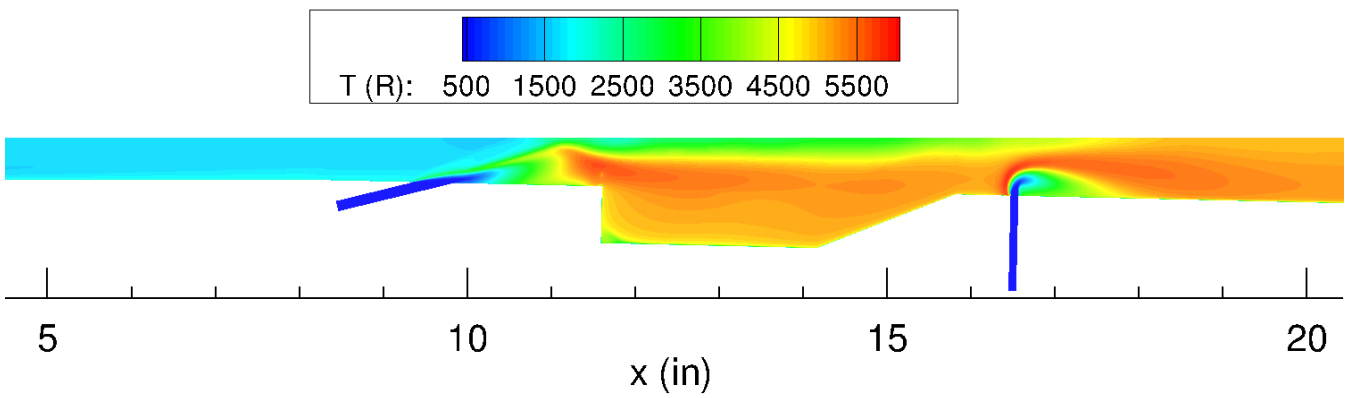

(a) Static temperature

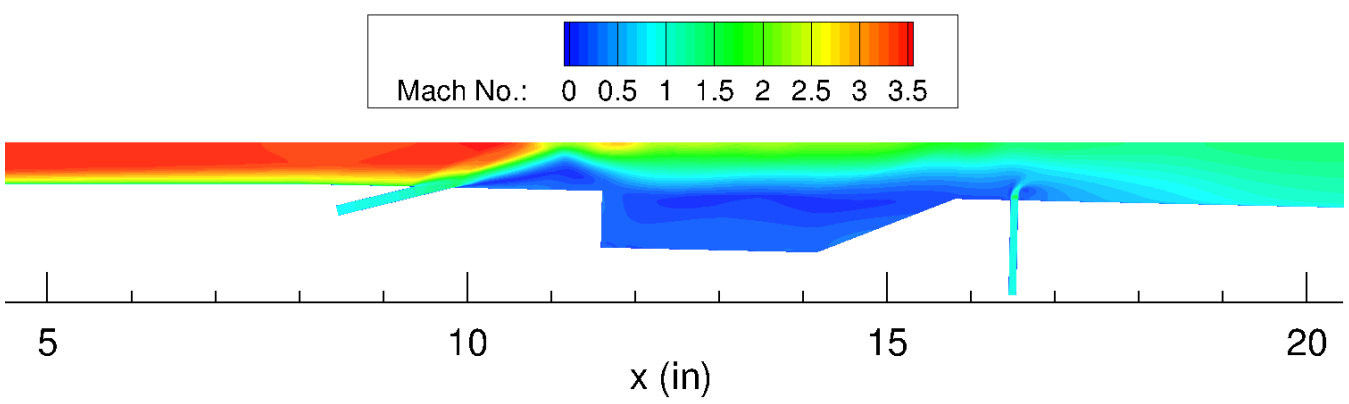

(b) Mach number

Figure 10. Calculated combustor flow field through injectors near sidewall for the Mach 8.0 case. 


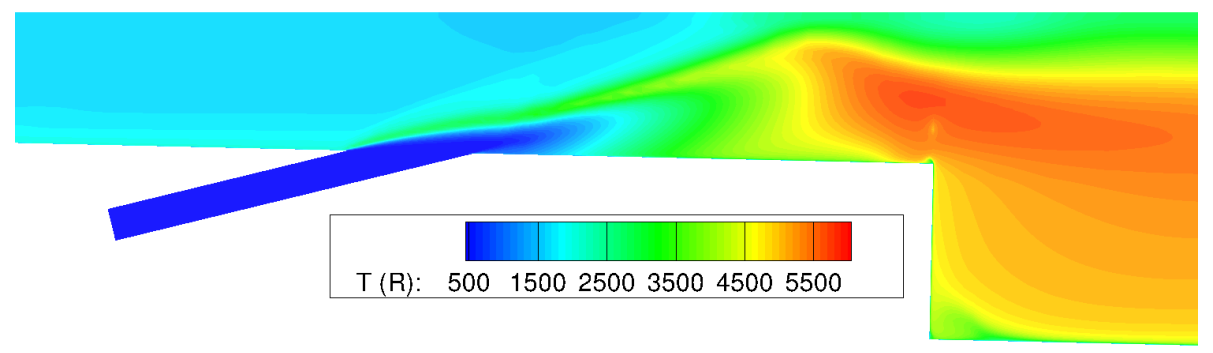

(a) Static temperature

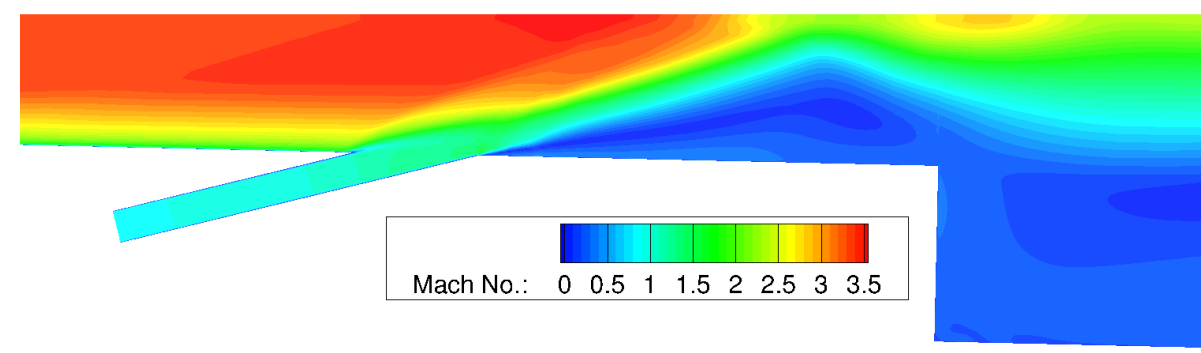

(b) Mach number

Figure 11. Closeup view of calculated combustor flow field surrounding primary injector near sidewall for the Mach 8.0 case.

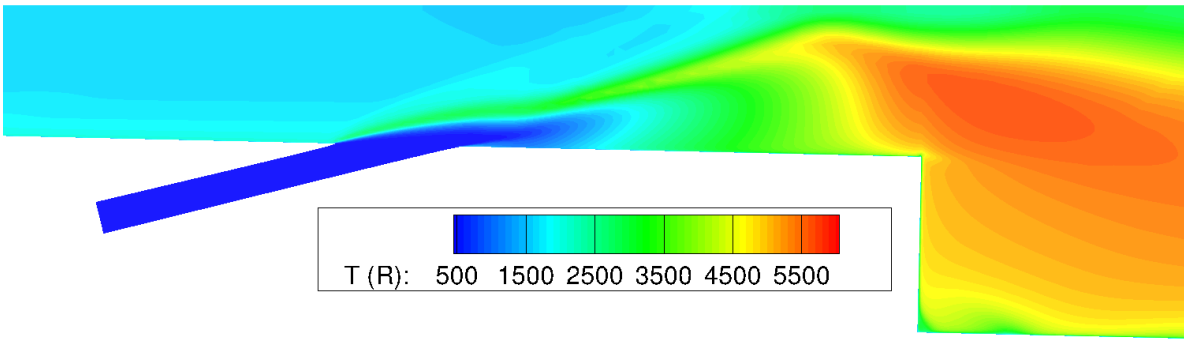

(a) Static temperature

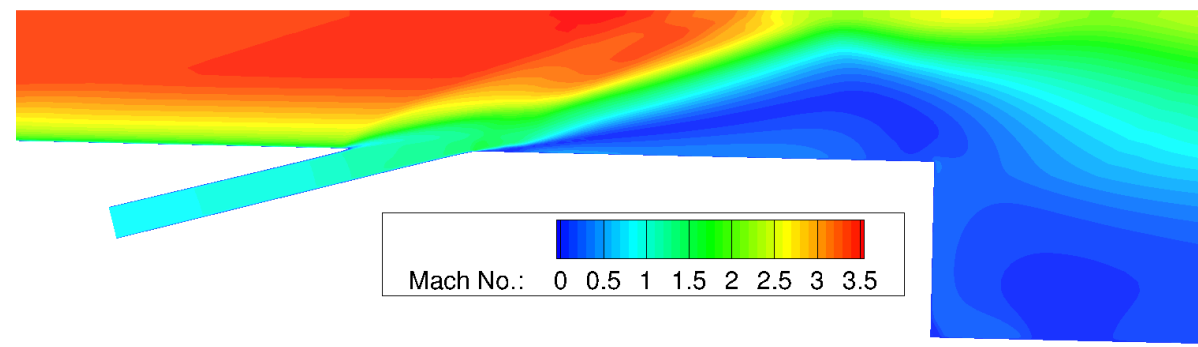

(b) Mach number

Figure 12. Closeup view of calculated combustor flow field through injectors nearest centerline for the Mach 8.0 case. 


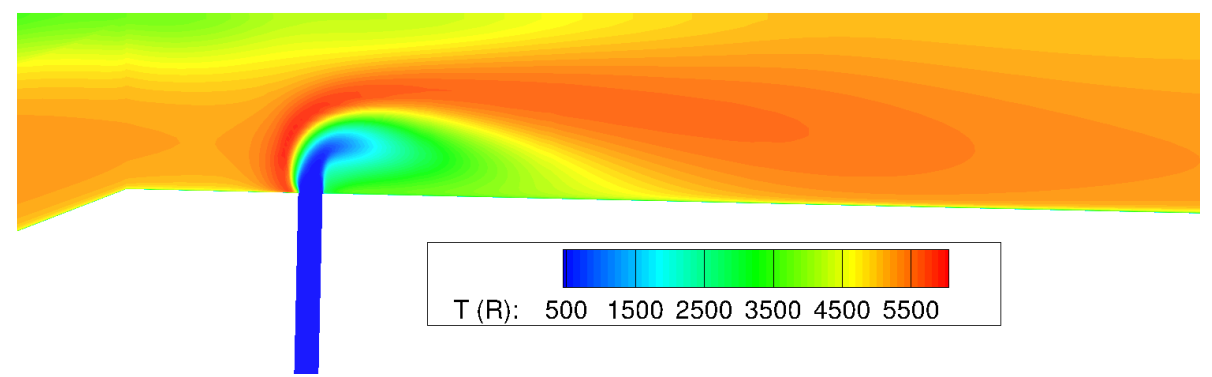

Figure 13. Closeup view of calculated combustor temperature field surrounding secondary injector near sidewall for the Mach 8.0 case.

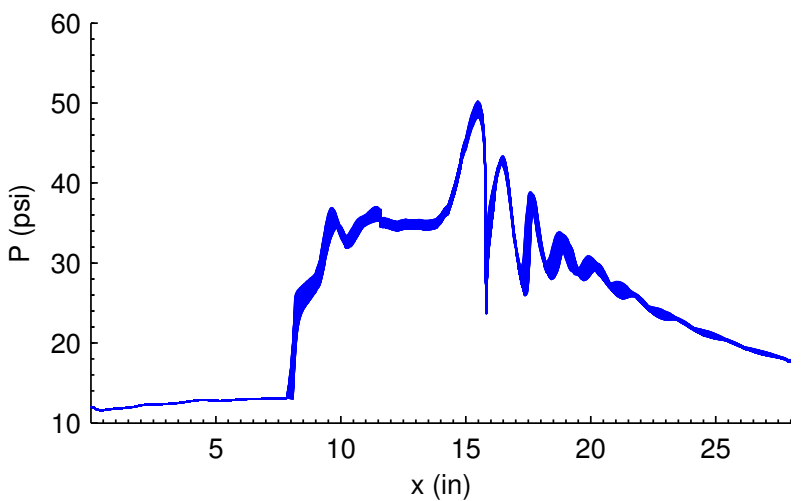

(a) $S c_{t}=0.40$

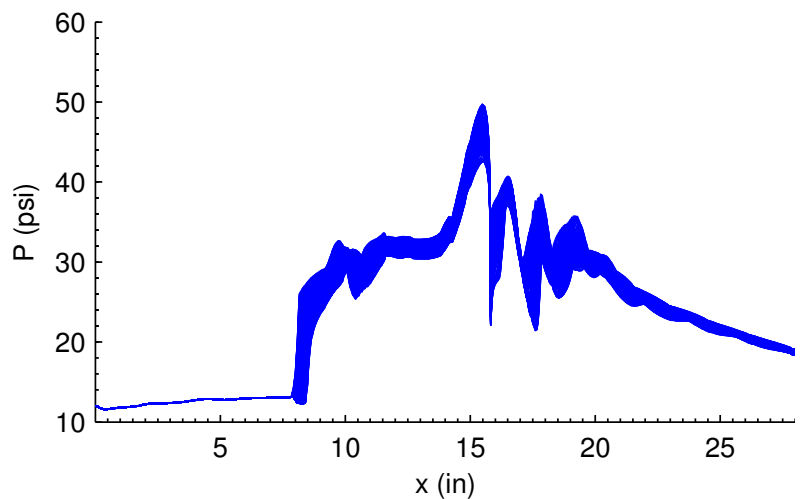

(b) $S c_{t}=0.70$

Figure 14. Locus of pressure variations for the Mach 5.8 case, SST model.

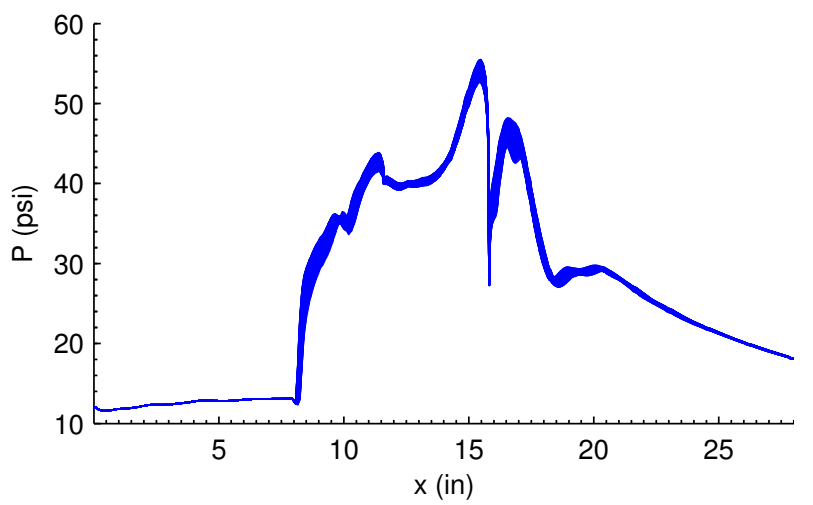

(a) $S c_{t}=0.40$

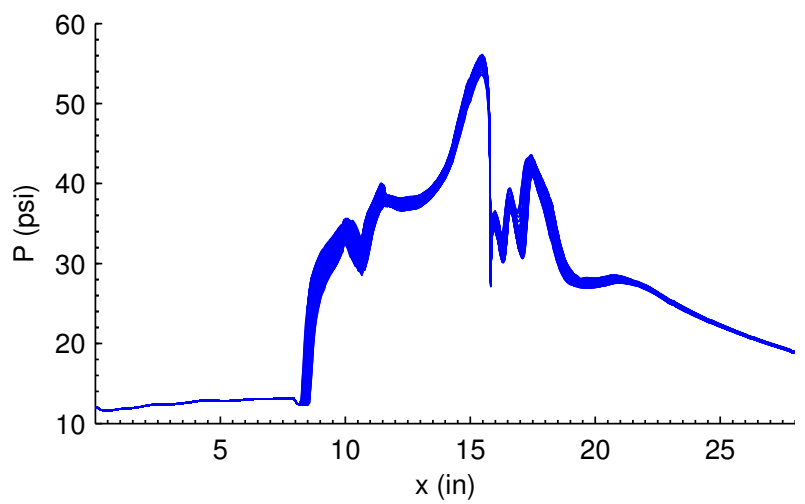

(b) $S c_{t}=0.70$

Figure 15. Locus of pressure variations for the Mach 5.8 case, SST model with $a_{1}=0.355$. 


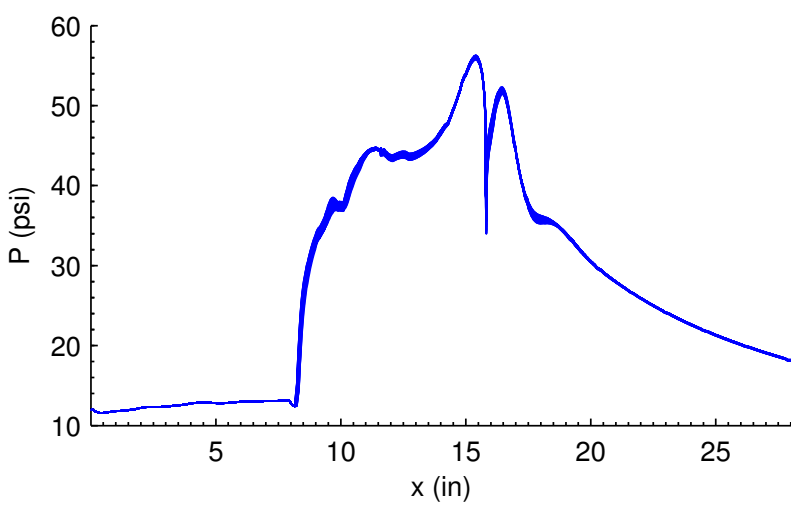

(a) $S c_{t}=0.40$

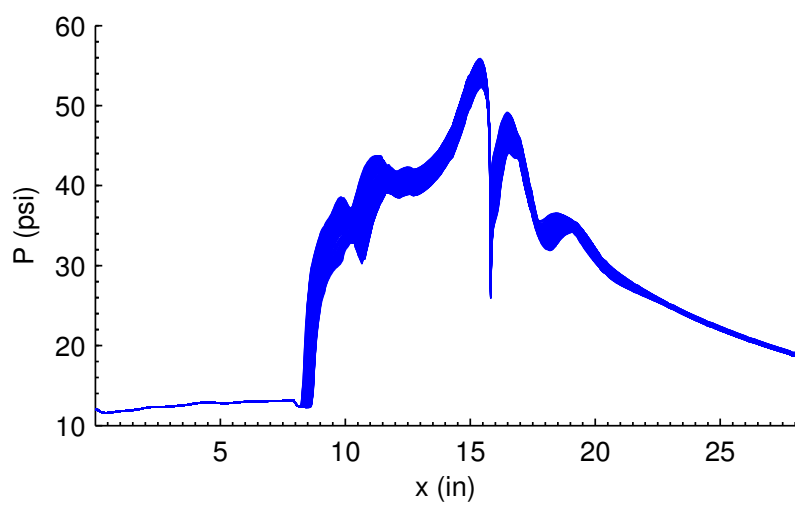

(b) $S c_{t}=0.70$

Figure 16. Locus of pressure variations for the Mach 5.8 case, BSL model.

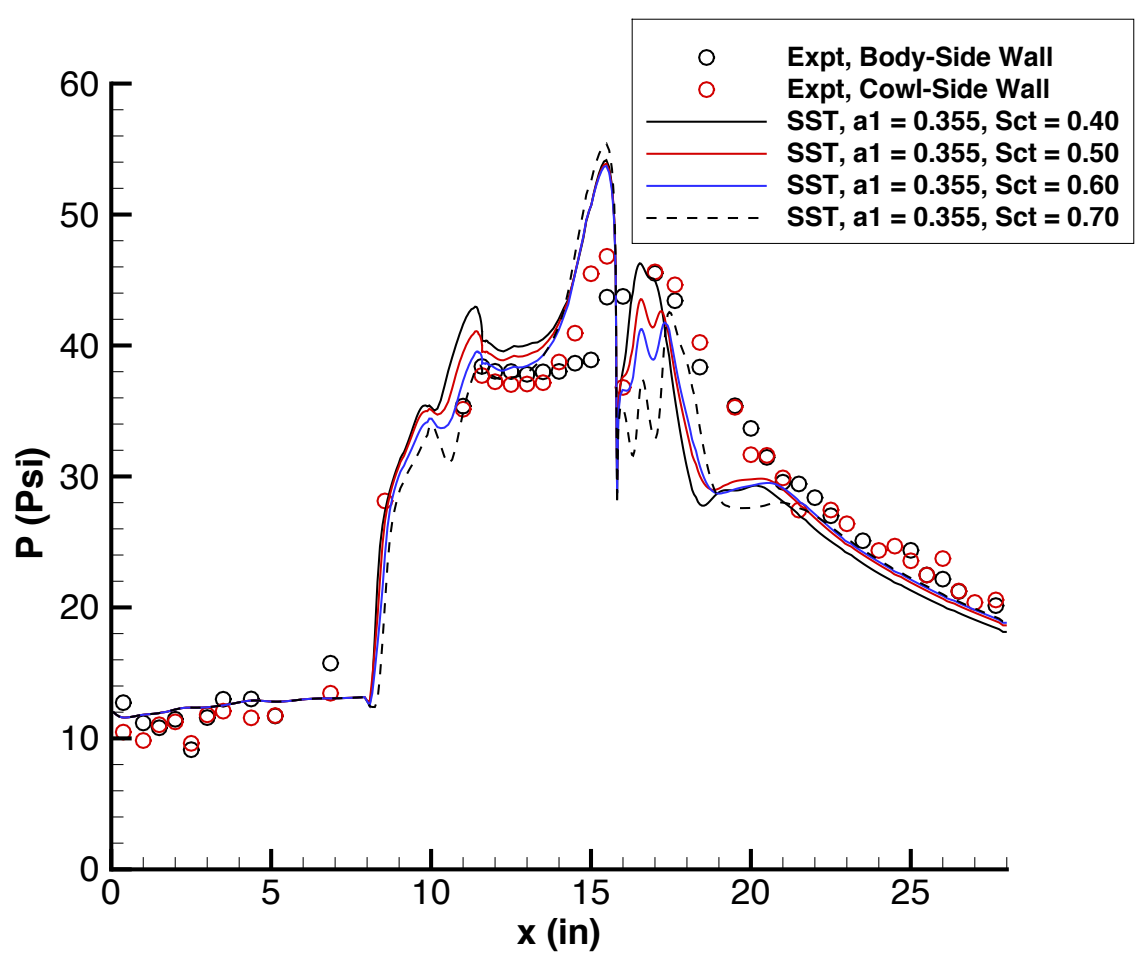

Figure 17. Static pressure distributions for the Mach 5.8 flight condition, SST with $a_{1}=0.355, S c_{t}$ variations. 


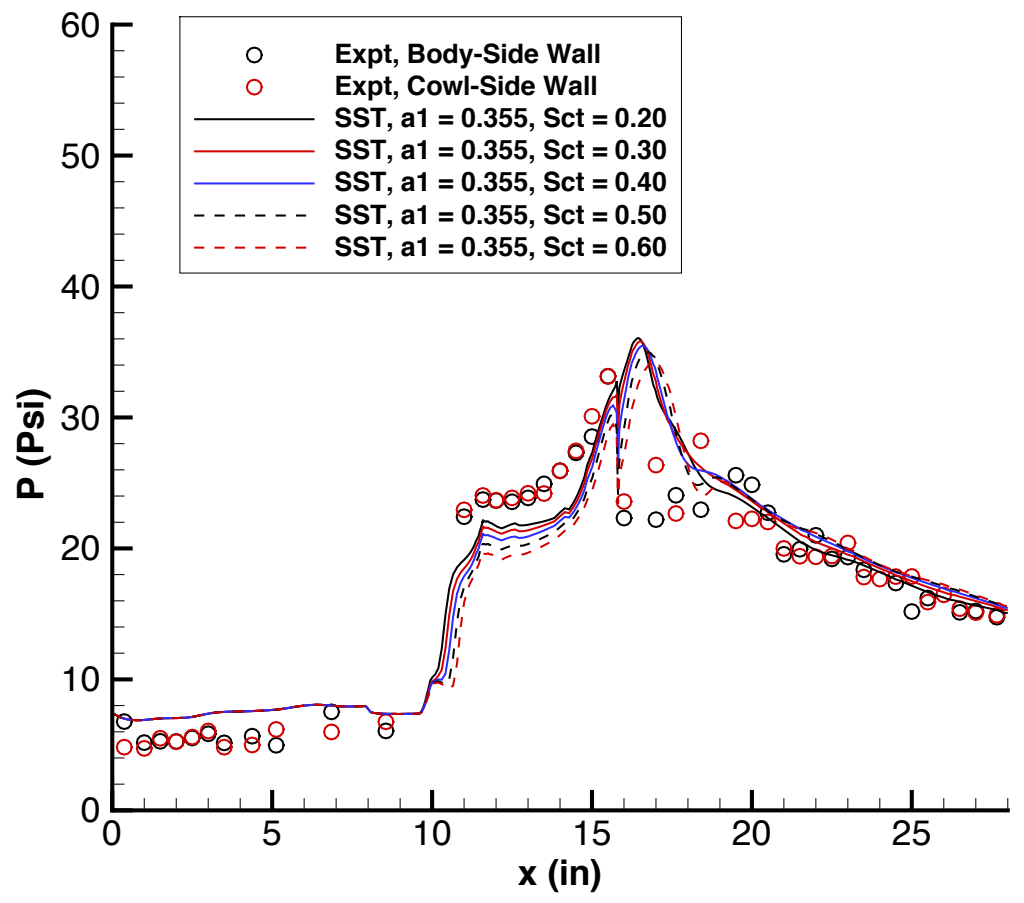

Figure 18. Static pressure distributions for the Mach 8.0 flight condition, SST with $a_{1}=0.355, S c_{t}$ variations. 


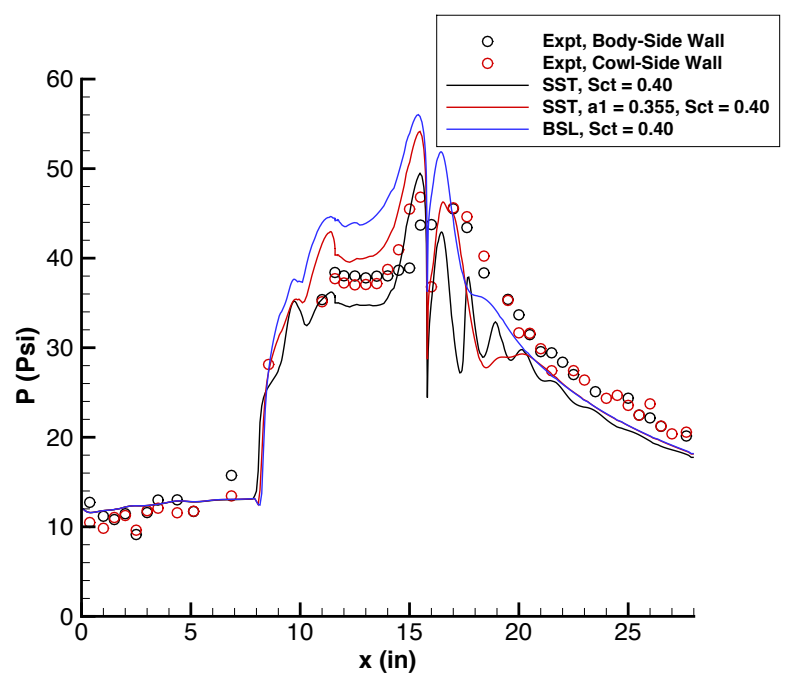

(a) $S c_{t}=0.40$

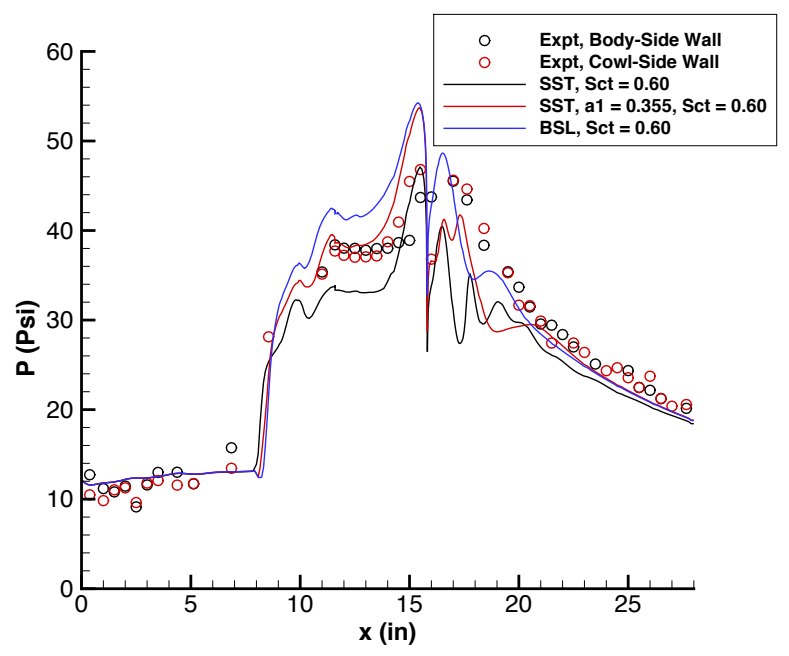

(c) $S c_{t}=0.60$

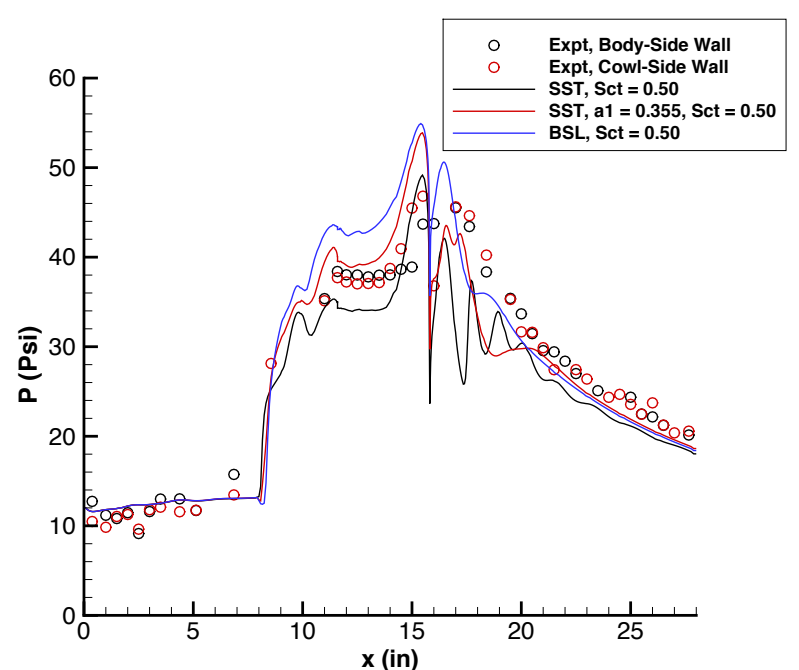

(b) $S c_{t}=0.50$

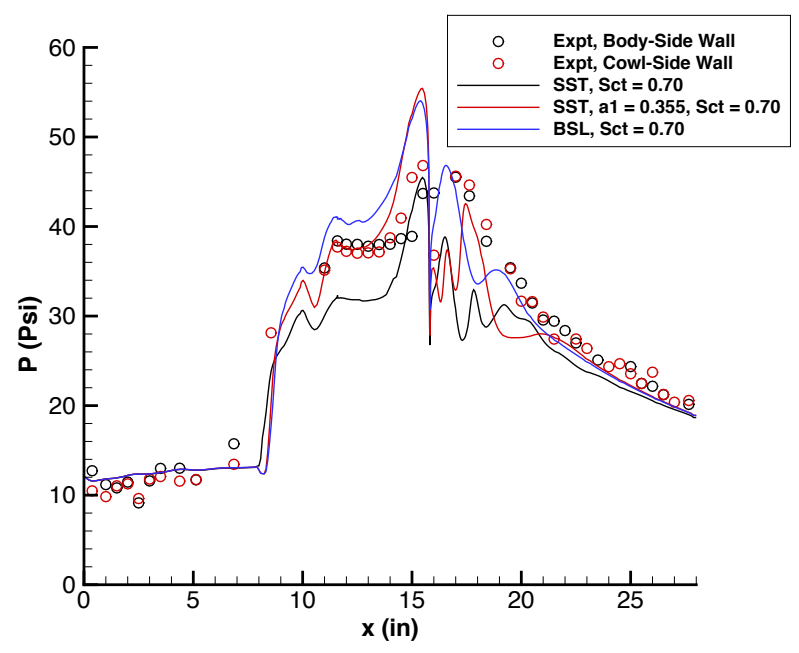

(d) $S c_{t}=0.70$

Figure 19. Static pressure variations for the Mach 5.8 case, turbulence model variations. 


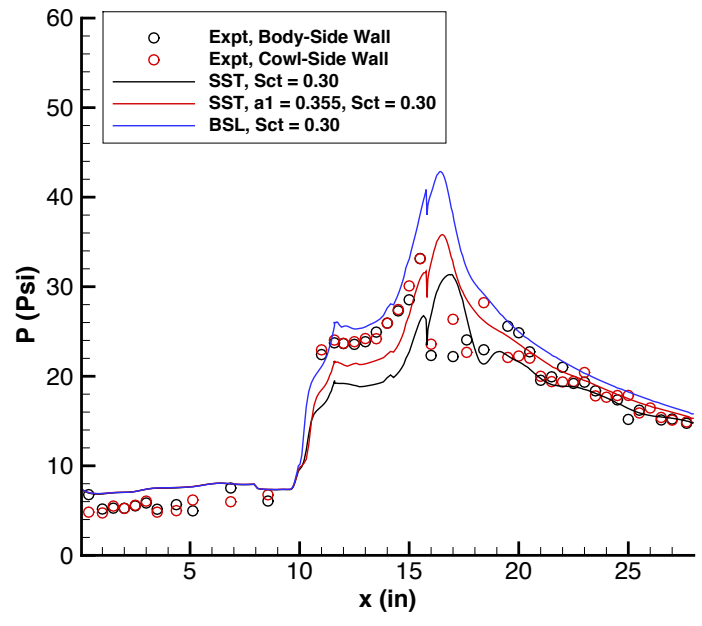

(a) $S c_{t}=0.30$

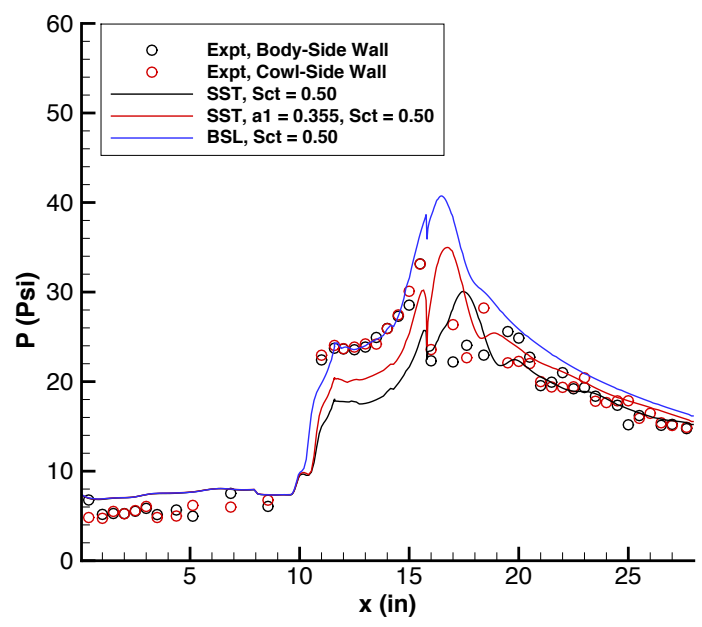

(c) $S c_{t}=0.50$

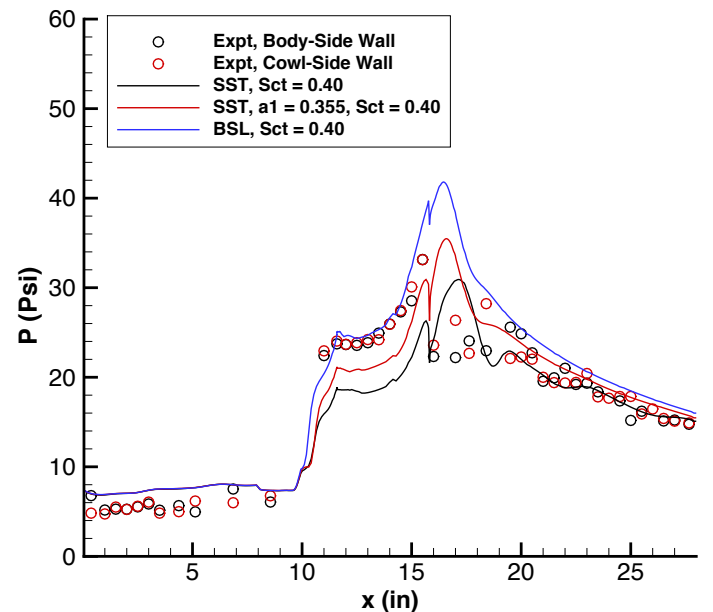

(b) $S c_{t}=0.40$

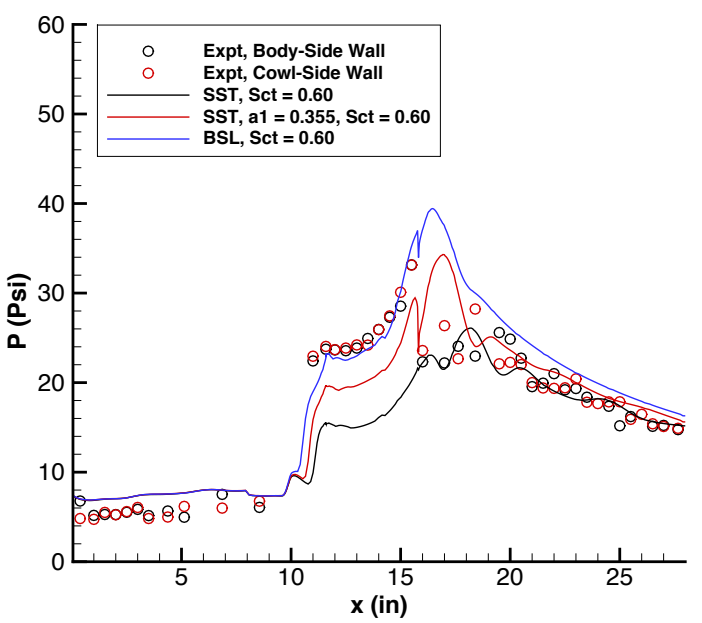

(d) $S c_{t}=0.60$

Figure 20. Static pressure variations for the Mach 8.0 case, turbulence model variations. 